\title{
Detection and Determination of Phenolic Compounds Released from Plastic Ware by the 4-Aminoantipyrine Method
}

\author{
(Received January 16, 1990)
}

\author{
Hajimu Ishiwata ${ }^{* 1}$, Rosario E. Martin ${ }^{* 2}$, Takiko Sugita ${ }^{* 1}$ and Kunitoshi Yoshinira*1 \\ $\left({ }^{* 1}\right.$ National Institute of Hygienic Sciences: 1-18-1, Kamiyoga, Setagaya-ku, Tokyo, Japan; \\ ${ }^{* 2}$ Bureau of Food and Drugs, Department of Health: Alabang, Muntinlupa, \\ Metro Manila, Philippines)
}

\begin{abstract}
Applicability of the 4-aminoantipyrine method for the determination of phenol released from plastic ware in contact with food was examined. Currently a turbidimetric method which has been shown to be less reliable is designated by the Food Sanitation Law for the regulation of phenol. Among 49 phenolic compounds, including phenol, used to manufacture plastics and related materials, 21 compounds, excluding two compounds which developed color without 4 aminoantipyrine, developed color by the 4 -aminoantipyrine method in the presence of $50 \%$ (v/ v) acetonitrile. In each instance, the optical density produced was at least $10 \%$ of that obtained for phenol. The 4-aminoantipyrine method was also applied to the water extract solutions of phenol resins. From 2.9 to $6.0 \mathrm{ppm}$ of 4 -aminoantipyrine-positive compounds (as phenol) was detected, while none was detected in the water extract solutions of polyvinyl chloride, polyethylene, polypropylene, polystyrene and polycarbonate products. More than $97 \%$ of the 4 -aminoantipyrine-positive compounds in the extract solution obtained from phenolic resins was identified as phenol with a three-dimensional high performance liquid chromatogram. These results indicated that the 4-aminoantipyrine method is applicable to the detection and determination of phenol in the water extract solution of plastic ware.
\end{abstract}

Key words: phenol; phenolic compounds; phenol resin; 4-aminoantipyrine; migration test; antioxidants; UV-absorbers; high performance liquid chromatography(photodiode array detector)

Leachable phenol from plastic ware made of formaldehyde, rubber products, and resincoated cans is regulated by the Japanese Food Sanitation Law $^{1)}$. There are two official methods to analyze phenol: a) the 4-aminoantipyrine (4-AA) method-a spectrophotometric method, and b) the bromine method-a turbidimetric method. The 4-AA method is applied to extract solutions from rubber products and protective coatings in cans, while the bromine method is used for extract solutions from formaldedhyderesins such as phenolic resin products. In a previous study ${ }^{2}$, we reported that the 4-AA method is more sensitive and effective than the bromine method. Although it is known that the 4-AA method is not specific to phenol but also responds to other phenolic compounds ${ }^{3)}$, the 4AA method is actually used for the quantitative analysis of phenol extracted from phenolic resin products $^{4), 5)}$.

This study was designed to examine the applicability of the 4-AA method to phenolic compounds used to manufacture phenolic resin and other plastics, and employed high performance liquid chromatography (HPLC) to determine phenol in extract solutions obtained from phenolic resin products.

\section{Materials and Methods}

\section{Samples}

Three types of tableware made of phenolic resin*3, one kind of bowl and two kinds of boxes,

*3 The tableware used in the present experiments was coated with polyurethane or natural resin, and the phenolic resin contained $55 \%$ powdered wood. Thus they were not "phenolic resin" according to the specification in the Japanese Food Sanitation Law. These samples are the same products as used in the previous study ${ }^{2}$. 
and a polyethylene bag, a polyvinyl chloride box, a polypropylene cup, a polystyrene box and a polycarbonate bottle were purchased from a department store and a supermarket in Tokyo. The phenolic resin products were coated with natural resin (the bowl) or polyurethane (the two boxes).

\section{Apparatus and operating conditions}

1) Spectrophotometer: Shimadzu UV-240.

2) High performance liquid chromatograph

i) For the detection of phenolic compound4-AA complexes, a Shimadzu LC-6A equipped with a column (Yanapak ODS A, $4.6 \mathrm{~mm}$ inner diameter and $250 \mathrm{~mm}$ length), a detector (Shimadzu SPD-6AV), and an integrator (Shimadzu Chromatopac C-R6A) was used. A mixture of water and acetonitrile $(2: 1, \mathrm{v} / \mathrm{v})$ was used as the mobile phase for components used in the production of phenolic resin, and a mixture of water and acetonitrile $(1: 1, \mathrm{v} / \mathrm{v})$ was used as the mobile phase for additives. The flow rate of the mobile phase was $0.8 \mathrm{ml} / \mathrm{min}$, the column oven temperature was $45^{\circ} \mathrm{C}$, the detection wavelength was $486 \mathrm{~nm}$, and the attenuation was 0.16 .

ii) For the identification of phenol, a JASCO 880-PU equipped with a column (Yanapak ODS A, $4.6 \mathrm{~mm}$ inner diameter and $250 \mathrm{~mm}$ length) and a Shimadzu SPD-M6A photodiode array UV-VIS detector was used. A Shimaduz M6A Multipac I system disk Version 1.25 was used for data analysis of chromatograms. A mixture of $0.1 \mathrm{M}$ phosphate buffer solution ( $\mathrm{pH} \mathrm{2.1)}$ and acetonitrile $(3: 1, \mathrm{v} / \mathrm{v})$ was used as a mobile phase. The flow rate was $1.2 \mathrm{ml} / \mathrm{min}$, and the column oven temperature was $45^{\circ} \mathrm{C}$.

\section{Reagents and test solutions}

Phenolic compounds, reagent grade or industrial grade, were purchased from Tokyo Kasei Kogyo Co., Ltd. Other reagents were of reagent grade from Wako Pure Chemical Industries, Ltd.

1) Phenolic compounds examined in the present experiments are shown in Tables 1,2 and 3. Most of these phenolic compounds are used in the manufacture of plastic tableware and food packaging materials. These compounds were dissolved in acetonitrile to make $0.1 \mathrm{~m} M$ or 1.0 $\mathrm{m} M$ standard solutions. In the case of phenol, both water and acetonitrile solutions were pre- pared as standard solutions.

2) 4-AA solution: $0.136 \mathrm{~g}$ of 4 -AA was dissolved in water and made up to $100 \mathrm{ml}$.

3) Borate buffer solution: $70 \mathrm{ml}$ of $1 \mathrm{M}$ sodium hydroxide solution and $100 \mathrm{ml}$ of $1 \mathrm{M}$ boric acid solution were mixed ( $\mathrm{pH} \mathrm{10.0).}$

4) Potassium ferricyanide solution: $0.86 \mathrm{~g}$ of potassium ferricyanide was dissolved in water. After the addition of $0.18 \mathrm{ml}$ of aqueous ammonia, the mixture was made up to $100 \mathrm{ml}$ with water.

5) Bromine-saturated water: $100 \mathrm{ml}$ of water was added to $3 \mathrm{ml}$ of bromine. The upper phase of the mixture was used after thorough shaking.

6) Acetylacetone solution: $150 \mathrm{~g}$ of ammonium acetate was dissolved in water, and $3 \mathrm{ml}$ of acetic acid and $2 \mathrm{ml}$ of acetylacetone were added. The mixture was made up to $1,000 \mathrm{ml}$ with water.

\section{Preparation of specimens and extraction of phenolic compounds}

The phenolic resin products were cut into pieces of suitable size (approximately $4 \mathrm{~cm} \times 10$ $\mathrm{cm}$ ) with an electric saw, the coating resin was removed with sandpaper, and the pieces were rinsed with water. Other plastic products were cut into pieces of almost the same size with scissors. These pieces were used as specimens. A specimen was put in a beaker and water which had been heated to $60^{\circ} \mathrm{C}$ was poured onto it. The amount of water was equivalent to $2 \mathrm{ml}$ per $1 \mathrm{~cm}^{2}$ of surface area of the specimen. The beaker was covered with a watch glass and kept at $60^{\circ} \mathrm{C}$ for $30 \mathrm{~min}$. The specimen was removed, and the solution was used as the extract solution for the detection and determination of phenolic compounds.

\section{Determination of phenolic compounds}

To $4 \mathrm{ml}$ of the extract solution or the standard solution, $0.6 \mathrm{ml}$ of the borate buffer solution, 0.5 $\mathrm{ml}$ of the 4-AA solution and $0.5 \mathrm{ml}$ of the potassium ferricyanide solution were added, and the volume was made up to $20 \mathrm{ml}$ with water ${ }^{2}$. In the case of the modified 4-AA method, $10 \mathrm{ml}$ of acetonitrile was added $(6 \mathrm{ml}$ of acetonitrile was added when the standard solution had been prepared with acetonitrile) before making up the volume to $20 \mathrm{ml}$ with water. The reaction mix- 


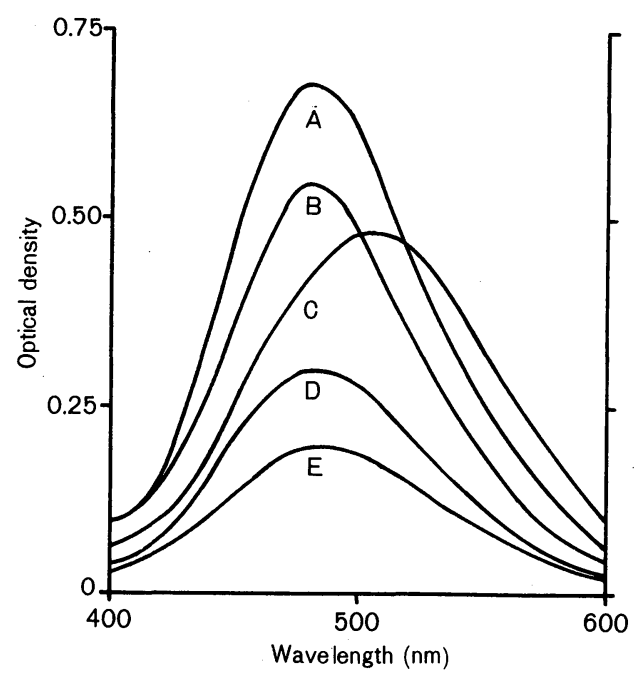

Fig. 1. Effect of water-soluble organic solvents on the $\lambda_{\max }$ and optical density of phenol by the 4-AA method

The reaction mixture containing $4 \mathrm{ml}$ of $0.2 \mathrm{~m} M$ phenol was made up to $20 \mathrm{ml}$ with water after addition of $10 \mathrm{ml}$ of organic solvent.

A, acetonitrile; $\mathrm{B}$, acetone; $\mathrm{C}$, water; $\mathrm{D}$, ethanol; E, methanol

ture was left at room temperature $\left(23 \pm 2^{\circ} \mathrm{C}\right)$ for $20 \mathrm{~min}$, then the optical density was measured at $505 \mathrm{~nm}$ and at the $\lambda_{\max }$ of the reaction mixture. Results are shown as equivalents to 0.1 $\mathrm{m} M$ phenolic compounds when $1.0 \mathrm{~m} M$ standard solutions were used.

\section{Preparation of the test solution for HPLC}

The reaction product of a phenolic compound with 4-AA prepared by the modified method described in section 5 was extracted with $2 \mathrm{ml}$ of methylene chloride. The organic solvent layer was taken and evaporated, and the residue was dissolved in a definite volume of acetonitrile. The acetonitrile solution was used as a test solution for HPLC.

\section{Detection of phenol by the reaction with bro- mine}

The detection of phenol in the aqueous extract solutions from phenolic resin was carried out by the official method specified in the Food Sanitation Law of Japan ${ }^{1}$. Visual observation of precipitate formation was performed by $12 \mathrm{vol}-$

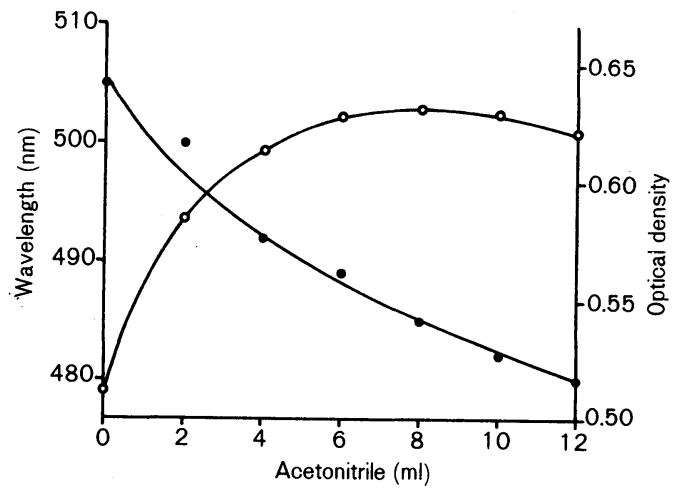

Fig. 2. Effect of the added volume of acetonitrile on the $\lambda_{\max }$ and optical density of phenol by the 4-AA method

The reaction mixture containing $4 \mathrm{ml}$ of $0.2 \mathrm{mM}$ phenol was made up to $20 \mathrm{ml}$ with water after the addition of a definite volume of acetonitrile.

๑, wavelength at $\lambda_{\max } ; \bigcirc$, optical density

unteers working at the institute. The results were scored using the following point system: detection of precipitate (1 point); no detection of precipitate ( 0 point); judgement of the presence of precipitate was difficult ( 0.5 point). The points were added, and the total points were divided by the number of volunteers. Results are shown as percent detection.

\section{Determination of formaldehyde}

An acetylacetone method ${ }^{6)}$ was used. Namely, $5 \mathrm{ml}$ of acetylacetone solution was added to $5 \mathrm{ml}$ of the aqueous extract solution obtained from phenolic resin. The mixture was heated in boiling water, and the optical density at $415 \mathrm{~nm}$ was measured after cooling.

\section{Results and Discussion}

1. Effect of solvents on color development of phenolic compounds reacted with 4-AA

The migration test of phenol is usually carried out with water as an extraction solvent, and the color development reaction of phenol with 4-AA is also carried out in water ${ }^{1), 4,5)}$. But the solubility of phenolic compounds in water is different from compound to compound. As a result, it is necessary to prepare standard solutions with organic solvents to examine the reactivity with 4-AA because the solubility of most phenolic 


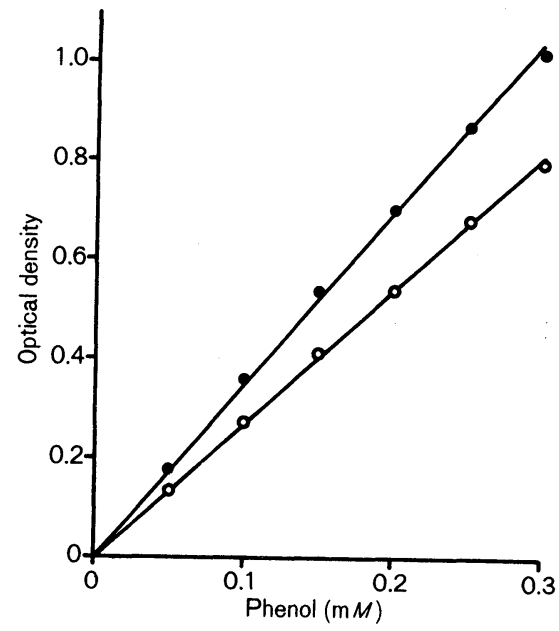

Fig. 3. Comparison of calibration curves of phenol by the original and the modified 4 -AA methods

In the case of the modified 4-AA method, $10 \mathrm{ml}$ of acetonitrile was added to the reaction mixture.

-, modified 4-AA method (determined at $482 \mathrm{~nm}$ ); $\mathrm{O}$, original 4-AA method (determined at $505 \mathrm{~nm}$ )

compounds in water is very low.

Among four kinds of water-soluble organic solvents, the highest optical density was observed in acetonitrile when phenol was reacted with 4-AA in the presence of $10 \mathrm{ml}$ of an organic solvent (Fig. 1). The $\lambda_{\max }$ values of the complex in water and acetonitrile were $505 \mathrm{~nm}$ and 482 $\mathrm{nm}$, respectively, and the optical density in acetonitrile was higher than that in other solvents at each $\lambda_{\max }$. The $\lambda_{\max }$ shifted to shorter wavelength with increase in the volume of acetonitrile. The highest optical density was observed between 6 and $10 \mathrm{ml}$ of acetonitrile (Fig. 2). The optical density of the reaction mixture was stable between 10 and $60 \mathrm{~min}$ after the reaction, but decreased to $98 \%$ at $2 \mathrm{~h}$ and $94 \%$ at $4 \mathrm{~h}$ after the reaction. A calibration curve for phenol was prepared by the modified 4 -AA method, e.g., addition of $10 \mathrm{ml}$ of acetonitrile, and determination of optical density at the $\lambda_{\max }, 482 \mathrm{~nm}$, after $20 \mathrm{~min}$. The plot was linear up to $0.3 \mathrm{mM}$. The correlation equation of optical density $(y)$ and the concentration $(\mathrm{m} M)$ of phenol $(x)$ was: $y=3.323 x+0.0328, r=0.999$, where $r$ is the correlation coefficient. The cal- ibration curve obtained by the original method was: $y=2.660 x+0.009, r=0.999$. The calibration curves obtained by the original 4-AA method" ${ }^{1)}$ and by the modified method are compared in Fig. 3. These results indicated that acetonitrile is not only a suitable solvent for making the standard solutions of phenolic compounds but also increases the sensitivity of the determination.

\section{Application of the modified 4-AA method to phenolic compounds used as components for the production of phenolic resin}

The modified 4-AA method was applied to 21 kinds of phenolic compounds, including phenol, which are used in the production of phenolic resin for tableware. The values of $\lambda_{\max }$ and optical density measured at $482 \mathrm{~nm}$, which was the $\lambda_{\max }$ of phenol by the modified method, and at $505 \mathrm{~nm}$, which was the $\lambda_{\max }$ of phenol by the original method, are shown in Table 1 . The color intensity developed at $0.1 \mathrm{mM}$ is shown as the relative optical density with respect to phenol. Eleven out of 20 phenolic compounds investigated developed relative color intensity amounting to more than $10 \%$ with respect to phenol. $m$-Cresol showed the highest relative optical density, $91 \%$ of that of phenol at each $\lambda_{\max }$. Resorcinol developed color upon the addition of ferricyanide solution with and without 4$\mathrm{AA}$, and the spectra of the two reaction mixtures were the same. The pigment formed from resorcinol was not extracted with methylene chloride though all other pigments formed by the reaction with 4 -AA were extracted. These facts indicated that the pigment may be the ferric salt of resorcinol. 2,2-Bis(4-hydroxyphenyl)propane, which developed $87 \%$ of the color intensity of phenol, is also used as a raw material for the synthesis of polycarbonate.

3. Application of the modified 4-AA method to phenolic antioxidants, $U V$-absorbers and some related phenolic compounds

Twenty-eight phenolic compounds used as antioxidants (Table 2) or UV-absorbers (Table 3) were examined. Also shown in Table 3 are results for four phenolic substances not used as additives for plastics: $p$-hydroxybenzoic acid, salicylic acid, 2,4-dihydroxybenzophenone, and 
Table 1. Application of the Modified 4-AA Method to Phenolic Compounds Used to Produce Phenolic Resin

\begin{tabular}{|c|c|c|c|c|c|}
\hline \multirow{2}{*}{ Compound } & \multirow{2}{*}{ CAS No. } & \multirow{2}{*}{$\frac{\lambda_{\max }}{(\mathrm{nm})}$} & \multicolumn{3}{|c|}{$\% \mathrm{OD}$ of $4-\mathrm{AA}$ complex at each wavelength } \\
\hline & & & $\lambda_{\text {maw }}$ & $482 \mathrm{~nm}$ & $505 \mathrm{~nm}$ \\
\hline Phenol & $108-95-2$ & 482 & 100 & 100 & 100 \\
\hline Resorcinol & $108-46-3$ & 466 & 50 & 47 & 46 \\
\hline 2,3-Xylenol & $526-75-0$ & 478 & 48 & 48 & 48 \\
\hline 2,4-Xylenol & $105-67-9$ & 463 & 4 & 4 & 3 \\
\hline 2,5-Xylenol & $95-87-4$ & 475 & 58 & 58 & 50 \\
\hline 2,6-Xylenol & $576-26-1$ & 478 & 47 & 47 & 48 \\
\hline 3,4-Xylenol & $95-65-8$ & - & - & 0 & 0 \\
\hline 3,5-Xylenol & $108-68-9$ & 550 & 38 & 17 & 30 \\
\hline$o$-Benzylphenol & $28994-41-4$ & 485 & 63 & 62 & 64 \\
\hline p-Phenylphenol & $101-53-1$ & - & - & 0 & 0 \\
\hline$p$-t-Butylphenol & $98-54-4$ & - & - & 1 & 1 \\
\hline$p$-t-Octylphenol & $140-66-9$ & - & - & 0 & 0 \\
\hline p-Nonylphenol & $104-40-5$ & - & - & 1 & 0 \\
\hline$p$-Cyclohexylphenol & $1131-60-8$ & - & - & 1 & 1 \\
\hline$o$-Cresol & $95-84-7$ & 480 & 78 & 78 & 77 \\
\hline$m$-Cresol & $108-39-4$ & 478 & 91 & 90 & 83 \\
\hline$p$-Cresol & $106-44-5$ & - & - & 1 & 0 \\
\hline$o$-Ethylphenol & $90-00-6$ & 480 & 68 & 68 & 66 \\
\hline$m$-Ethylphenol & $620-17-7$ & 478 & 89 & 89 & 82 \\
\hline$p$-Ethylphenol & $123-07-9$ & - & - & 1 & 0 \\
\hline 2,2-Bis(4-hydroxyphenyl)propane & $80-05-7$ & 482 & 87 & 87 & 87 \\
\hline
\end{tabular}

The optical density of the reaction mixture of phenol with 4-AA at each wavelength, 0.365 at $482 \mathrm{~nm}\left(\lambda_{\max }\right)$ and 0.325 at $505 \mathrm{~nm}$, was taken as $100 \%$. Optical density values of other phenolic compounds at the respective $\lambda_{\max }$ at the concentration corresponding to $0.1 \mathrm{mM}$ are shown as \% of that of phenol.

\section{$2,2^{\prime}, 4,4^{\prime}$-tetrahydroxybenzophenone.}

Four out of 16 antioxidants developed color with more than $10 \%$ relative intensity with respect to the optical density produced by phenol. The highest relative optical density was observed with $o$-phenylphenol $(95 \%$ of that of phenol at the respective $\lambda_{\max }$ ). Because the $\lambda_{\max }$ of phenol was at shorter wavelength than that of $o$-phenylphenol, the optical density of $o$-phenylphenol at $505 \mathrm{~nm}$ was higher than that of phenol. The acetonitrile solution of $4,4^{\prime}$. methylenebis (2,6 -di-t-butylphenol) showed a pale yellowish purple color which changed to reddish purple on alkalization by the addition of the borate buffer solution or diluted ammonia water. The $\lambda_{\max }$ of this solution was $573 \mathrm{~nm}$. The optical density of this solution fell to $1 / 5$ of the original value after the treatment for color development, but the $\lambda_{\max }$ did not change. It is unknown whether the color development of the reaction mixture was caused by the reaction product of the phenolic compound with 4-AA or by the unreacted compound. The optical density of the reaction mixture of $4,4^{\prime}$-methylenebis(2,6-di-t-butylphenol) with 4 -AA was $4 \%$ of that of phenol. 2,2'-Methylenebis-(6-t-butyl-p-cresol) did not develop color within $20 \mathrm{~min}$, but developed color with $\lambda_{\max } 579 \mathrm{~nm}$ after several hours.

Five kinds of phenolic UV-absorbers out of 8 showed more than $10 \%$ relative optical density with respect to phenol (Table 3). The highest relative optical density, $57 \%$, was observed with 2-hydroxy-4-methoxybenzophenone. The modified 4-AA method was also applied to some phenolic compounds having the same basic chemical structures as antioxidants or UVabsorbers, but not used in the production of plastic ware. One of these compounds, $p$ hydroxybenzoic acid, developed color which had a relative optical density of $88 \%$ with respect to phenol. Another, $2,2^{\prime}, 4,4^{\prime}$. tetrahydroxybenzophenone, also developed 


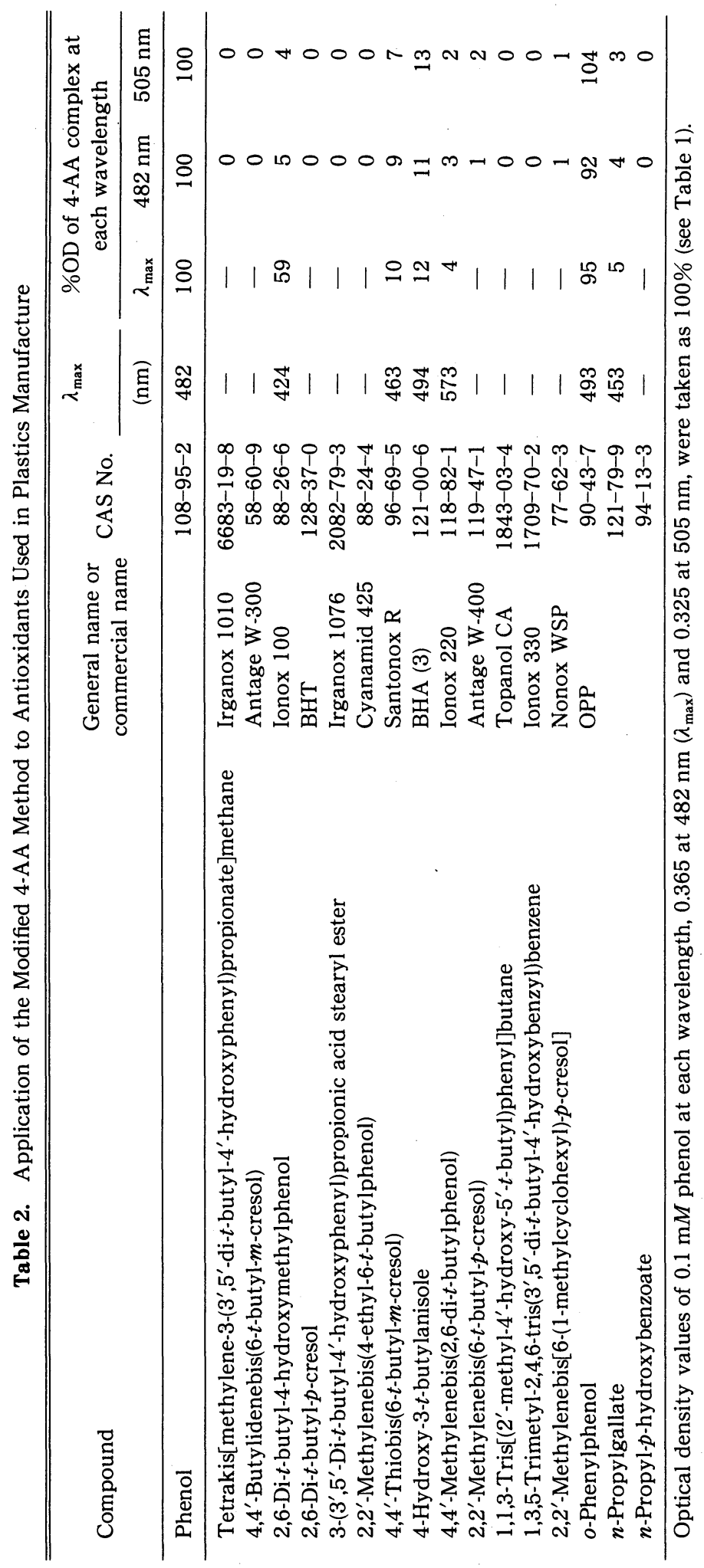




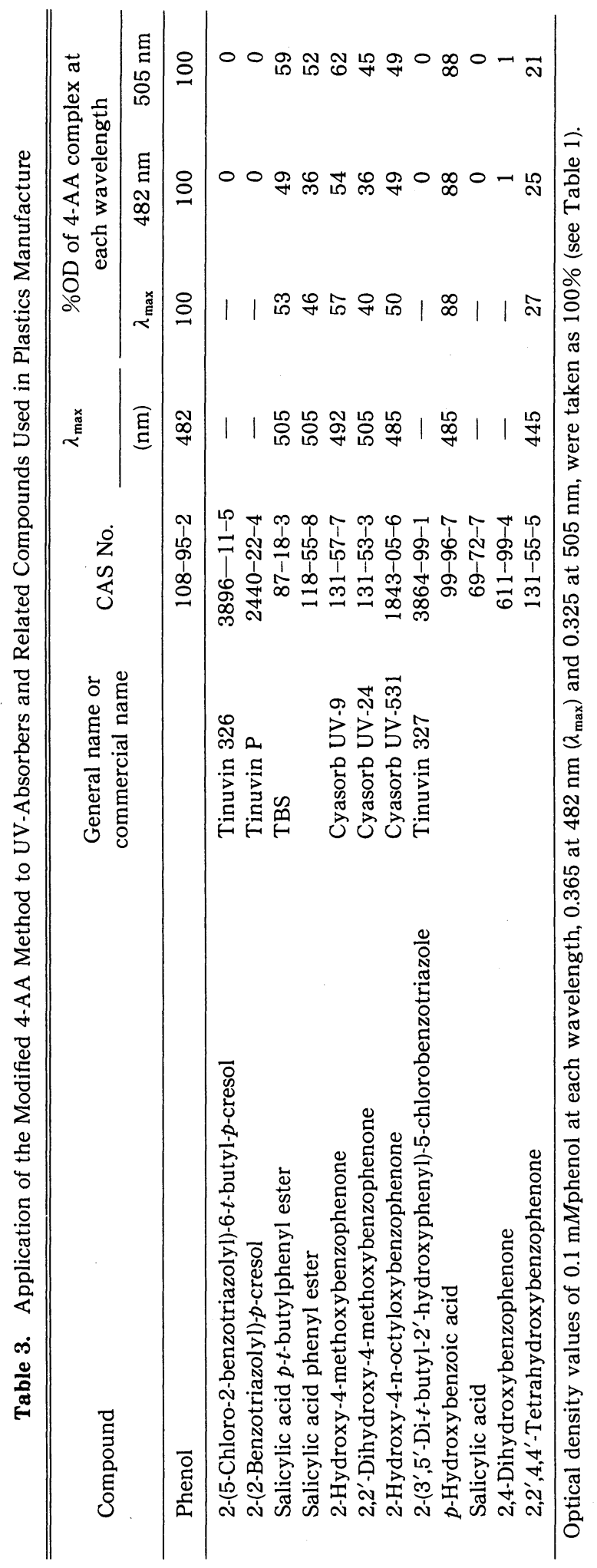




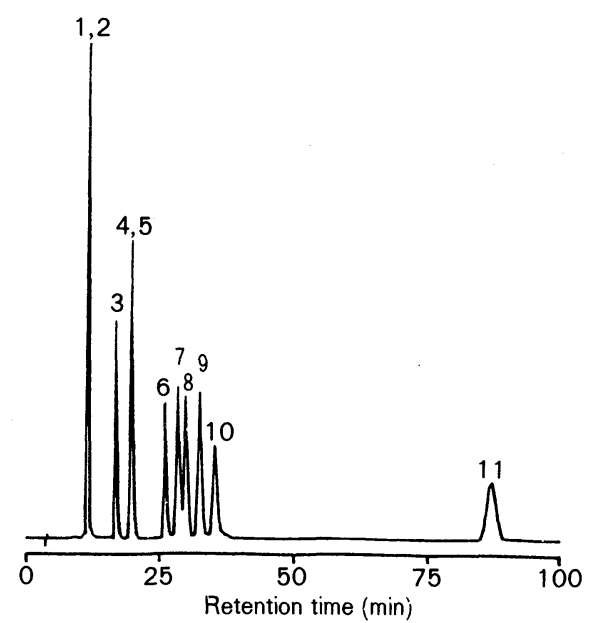

Fig. 4. High performance liquid chromatogram of 4-AA complex with phenolic compounds used as raw materials for phenolic resin manufacture

1, phenol; 2, 2,2-bis(4-hydroxyphenyl)propane; 3, o-cresol; $4, m$-cresol; $5, m$-xylenol; 6 , 2,6-xylenol; 7, o-ethylphenol; 8, $p$-xylenol; 9, $m$-ethylphenol; 10, 2,3 -xylenol; 11, obenzylphenol

color, but the produced pigment could not be extracted with methylene chloride, as in the case of resorcinol.

\section{High performance liquid chromatographic sep-} aration of phenolic compounds reacted with 4 $-A A$

HPLC was performed of the reaction products of 4-AA with the phenolic compounds extracted with methylene chloride from the reaction mixture. The chromatograms for the 4-AA complexes of components used to produce phenolic resin and those of additives are shown in Fig. 4 and in Fig. 5, respectively. In the former case, the chromatogram showed distinct peaks for each component, except for phenol and 2,2-bis(4hydroxyphenyl)propane, which appeared as a single overlapping peak (Fig. 4). In the case of the additives, $m$-cresol and $m$-xylenol gave identical retention times (Fig. 5). Phenol and 2,2-bis(4-hydroxyphenyl)propane again appeared at the same retention time, as in Fig. 4.

\section{Determination of aqueous leachable phenolic compounds from plastic products}

Phenolic compounds in the aqueous extract

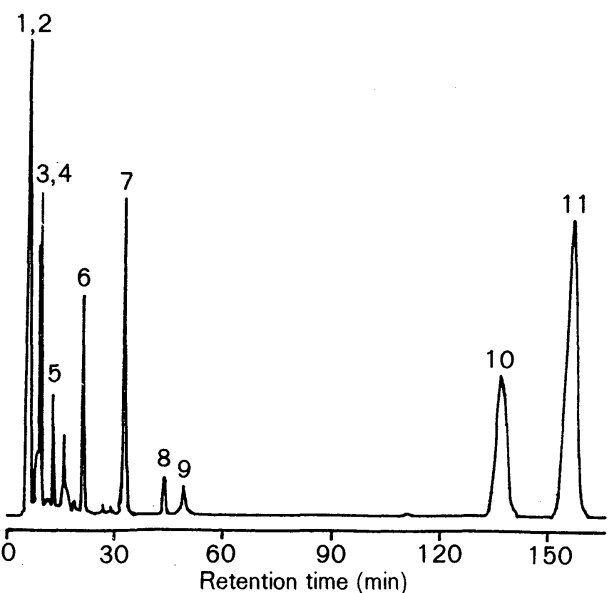

Fig. 5. High performance liquid chromatogram of 4-AA complex with phenolic compounds used as additives for plastics

1, phenol; 2, 2,2-bis(4-hydroxyphenyl)propane; 3, Cyasorb UV-24; 4, phenyl salicylate; 5, Cyasorb UV-9; 6, BHA; 7, Santonox R; 8 , OPP; 9, TBS; 10, Ionox 100; 11, Cyasorb UV531

solutions obtained from phenolic resin and some other plastic products used for tableware or food packaging were determined by the original 4-AA method, the modified 4-AA method and the bromine method. The concentration of phenolic compounds obtained by the two 4-AA methods are shown in Table 4 as the concentration of phenol. At approximately the same concentrations of phenol, the modified 4-AA method showed 1.4 times higher sensitivity than the original 4-AA method. Little work has been done on the migration of phenol from phenolic resins. Baba et al. ${ }^{4)}$ determined the leachable phenol from 4 kinds of phenolic resin products by the 4-AA method and obtained values between 0.1 and $0.3 \mathrm{ppm}$. The present results shown in Table 4 were 10 to 20 times higher. This difference may have arisen because a) our samples were not "phenolic resin" as specified by the Food Sanitation Law, and b) they were treated with sandpaper to remove the coating resin as described before. For these reasons, the concentrations of released phenol shown in Table 4 have no implications for the safety of tableware but do indicate a good correlation between the results obtained by the $4-\mathrm{AA}$ method and the modified method. 
Table 4. Determination of Leachable Phenolic Compounds and Formaldehyde

\begin{tabular}{lcccccc}
\hline \hline & \multicolumn{5}{c}{ Phenolic compounds*1 } & \\
\cline { 2 - 3 } & \multicolumn{2}{c}{ Original method } & & \multicolumn{2}{c}{ Modified method } & Formaldehyde \\
\cline { 2 - 3 } & $\begin{array}{c}\text { OD at } \\
\text { (ppm) }\end{array}$ & $\begin{array}{c}\text { Conc. } \\
\text { (ppm) }\end{array}$ & & $\begin{array}{c}\text { OD at } \\
482 \mathrm{~nm}\end{array}$ & $\begin{array}{c}\text { Conc. } \\
\text { (ppm) }\end{array}$ & \\
\hline Phenol soln. (10 ppm) & 0.304 & - & & 0.423 & - & \\
\hline Phenol resin Sample 1 & 0.086 & 2.8 & & 0.122 & 2.9 & 0.5 \\
Phenol resin Sample 2 & 0.186 & 6.1 & & 0.254 & 6.0 & 1.1 \\
Phenol resin Sample 3 & 0.098 & 3.2 & & 0.137 & 3.3 & 0.7 \\
Polyvinyl chloride & & ND*2 & & ND & \\
Polyethylene & & ND & & ND & \\
Polypropylene & & ND & & ND & \\
Polystyrene & & ND & & ND & \\
Polycarbonate & & ND & & ND & \\
\hline
\end{tabular}

*1 As phenol

*2 Less than $1 \mathrm{ppm}$

No color development was observed in the aqueous extracts of plastic products made of polyvinyl chloride, polyethylene, polypropylene, polystyrene and polycarbonate (Table 4). Because most of the antioxidants and UVabsorbers are very slightly soluble or insoluble in water, these phenolic compounds may not be leached from the samples. In Japan, antioxidants and UV-absorbers are not used in phenolic resin for food applications, ${ }^{7)}$ but they are used in other food packaging materials (polymers).

The relationship between the results obtained by the modified 4-AA method and the bromine method are shown in Fig. 6. The calibration curve for the bromine method was sigmoid, in contrast to the linear plot in the case of the modified 4-AA method. In the case of the extraction solutions obtained from phenolic resins, no relation was observed between the precipitate formation (\%) by the bromine method and the concentration of phenol determined by the modified 4-AA method, as shown in Fig. 6. Although the detection rate of precipitate by the bromine method in 5 ppm phenol standard solution was only $13 \%, 56 \%$ detection was observed in an extraction solution in which the phenol concentration determined by the modified 4-AA method was $6.0 \mathrm{ppm}$.

Phenolic resin is produced by the reaction of the phenolic compounds shown in Table 1 and formaldehyde. The leachable concentration of formaldehyde is required to be less than $4 \mathrm{ppm} .{ }^{1}$

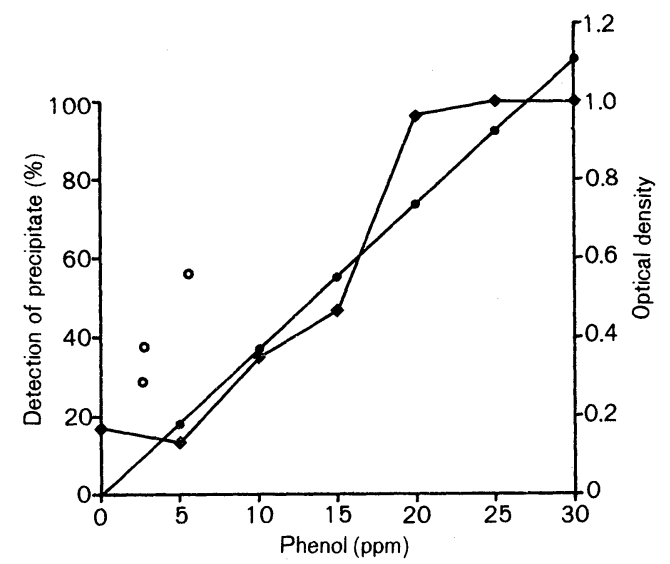

Fig. 6. Relation between the concentrations of phenol in the extract solution obtained from phenolic resin as determined by the modified 4-AA method and the bromine method

Extract conditions: the specimen of phenolic resin was soaked in $2 \mathrm{ml}$ of water per $1 \mathrm{~cm}^{2}$ of the surface of the specimen at $60^{\circ} \mathrm{C}$ for $30 \mathrm{~min}$.

Detection of precipitate by the bromine method: detection was carried out by each of 12 volunteers.

$\bigcirc$, extract solution; $\bullet$, calibration curve by the bromine method; calibration curve by the modified 4-AA method

Formaldehyde in the extraction solutions ranged from 0.5 to $1.1 \mathrm{ppm}$. Concentrations of phenol and formaldehyde released from the specimens differed by a factor of two between 


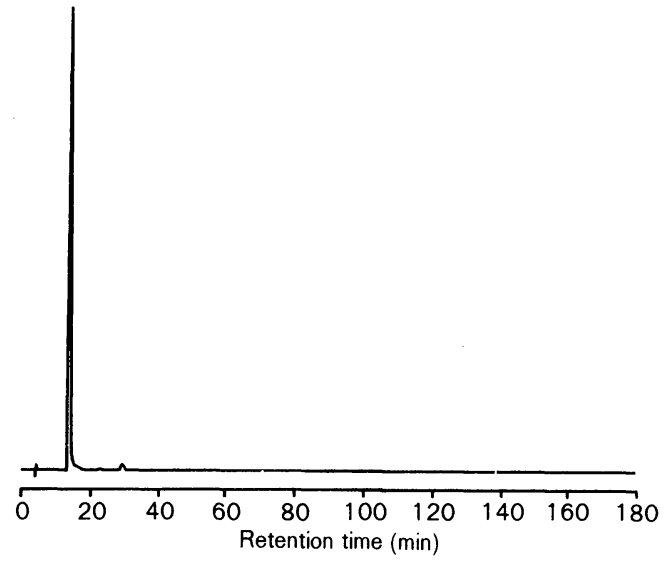

Fig. 7. High performance liquid chromatogram of the methylene chloride extracts from the reaction mixture of 4 -AA with the extract solutions obtained from phenolic resin

the highest and the lowest values obtained, but the molecular concentration ratios of formaldehyde to phenol in the extract solutions were almost the same, $0.6 \pm 0.1$ (average and standard deviation).

\section{Identification of phenol in the aqueous extract solutions obtained from phenolic resin prod- ucts}

HPLC was applied to the reaction mixture of 4 -AA with the extract solutions obtained from phenolic resin products to identify the phenolic compounds. In three of the phenolic resin extracts analyzed, the chromatograms were almost identical. A typical chromatogram is shown in Fig. 7. Two peaks were observed. The retention time and the visible spectrum of the main peak coincided with those of phenol and 2,2-bis(4-hydroxyphenyl)propane. However, the main peak was identified as phenol by three-dimensional HPLC using the extract solution obtained from phenolic resin which had not been treated with 4-AA (Fig. 8). This technique was carried out because the 4-AA complexes of phenol and 2,2-bis (4-hydroxyphenyl) propane have the same retention times and the same visible absorption spectra. In the three-dimensional HPLC, phenol was detected in the extract solutions obtained from phenolic resin products but 2,2-bis(4-hydroxyphenyl)propane was not. Thus, the main peak reacted with 4-AA shown

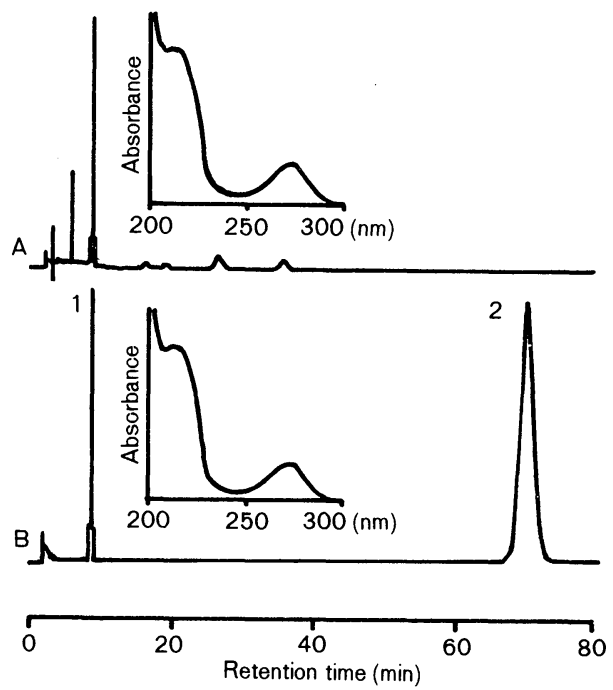

Fig. 8. High performance liquid chromatogram of the extract solution obtained from phenolic resin

The extract solution was not treated with 4-AA. The spectrum in each chromatogram is that of the peak at the retention time of $8.5 \mathrm{~min}$.

Detection wavelength: $270 \mathrm{~nm}$

A: Extract solution obtained from phenolic resin

B: Standard solution (1, phenol; 2, 2,2-bis(4-hydroxyphenyl)propane

in Fig. 7 was considered to be phenol. In Fig. 7, another unknown small peak appeared at the retention time of $29 \mathrm{~min}$, which is close to those of $o$-ethylphenol and $p$-xylenol. Phenol in Fig. 7 accounted for more than $97 \%$ and the unknown small peak for less than $1 \%$ of the total peak area. Therefore, most of the 4-AA-positive material in the aqueous extraction solutions from phenolic resin shown in Table 4 was phenol.

\section{Conclusion}

1. The reactivity with 4-AA of forty-nine phenolic compounds, most of which are used in plastics production, was examined. Among the 49 compounds including phenol, 21 compounds reacted with 4-AA and developed color with an optical density at the respective $\lambda_{\max }$ which was more than $10 \%$ of that of phenol at $0.1 \mathrm{mM}$. Two other phenolic compounds also developed reddish color which may be a consequence of the reaction with ferricyanide. In the compari- 
son of optical density at $\lambda_{\max }$ of each reaction mixture, $o$-phenylphenol showed the highest value, $95 \%$ of that of phenol.

2. Color development was observed in the reaction of 4-AA with the aqueous extract solutions from phenolic resin products prepared with water at $60^{\circ} \mathrm{C}$ for $30 \mathrm{~min}$, but not with the aqueous extracts from polyvinyl chloride, polyethylene, polypropylene, polystyrene and polycarbonate products.

3. More than $97 \%$ of the optical density of the reaction mixture of 4 -AA with the extract solution obtained from phenolic resin products was confirmed to be due to phenol by three-dimensional HPLC for both extract solution reacted with 4-AA and that not reacted with 4-AA.

4. These results indicate that the 4-AA method may be superior to the bromine method, the official method, for the detection and determination of phenol in the extract solution pre- pared from plastic products.

\section{References}

1) Ministry of Health and Welfare: "Notice No. 20, Kanpo" p. 32, February 16 (1982).

2) Ishiwata, H., Sugita, T., Yoshihira, K.: J. Food Hyg. Soc. Japan 30, 300 305 (1989).

3) Pharmaceutical Society of Japan: "Standard Methods of Analysis for Hygienic Chemists" p. 77 and 865 (1980), Kanehara Shuppan.

4) Baba, T., Hosokawa, M., Yamada, A.: J. Food Hyg. Soc. Japan 27, 311 315 (1986).

5) Kikuchi, H., Ushizawa, I.: Ann. Rep. Miyagi Pref. Inst. Bublic Health and Environ. 4, 152 153 (1986).

6) Sugita, T., Ishiwata, H., Yoshihira, K.: J. Food Hyg. Soc. Japan 29, 273 279 (1988).

7) Japan Thermosetting Plastics Industry Association "Positive List on Phenolic and Melamine Resins for Food Processing Equipment and Packaging" p. 15 (1983). 